\title{
PRODUÇÃO DO ESPAÇO URBANO E REGULARIZAÇÃO FUNDIÁRIA: CONSIDERAÇÕES A PARTIR DO ESTUDO DE ITUIUTABA-MG
}

\author{
Airton Batista Costa Neto Nepomuceno \\ Ministério Público do Estado de Minas Gerais, Ituiutaba, MG, Brasil \\ Universidade Federal de Uberlândia, Instituto de Ciências Humanas do Pontal, Programa de Pós-graduação em \\ Geografia do Pontal, Ituiutaba, MG, Brasil \\ airton neto@hotmail.com \\ Vitor Koiti Miyazaki \\ Universidade Federal de Uberlândia, Instituto de Ciências Humanas do Pontal, Programa de Pós-graduação em \\ Geografia do Pontal, Ituiutaba, MG, Brasil \\ vitor.ufu@ufu.br
}

\begin{abstract}
RESUMO
No âmbito do processo de produção do espaço urbano, problemas como déficit de moradias e a existência de ocupações irregulares são característicos em nossas cidades, diante da impossibilidade de parcela significativa da população se inserir no mercado imobiliário. Isto configura uma realidade preocupante nos centros urbanos brasileiros, favorecendo a configuração da denominada "cidade ilegal". Assim, torna-se necessário que a política de regularização fundiária seja fomentada pelo Poder Público, podendo ela ser definida como o processo de integração dos assentamentos irregulares ao contexto legal das cidades, através da adoção de medidas jurídicas, urbanísticas, ambientais e sociais. Constitui-se objetivo deste texto analisar áreas urbanas informais e compreender o processo de regularização fundiária na cidade de Ituiutaba. A metodologia adotada foi pautada em pesquisa bibliográfica e documental. A coleta de dados foi realizada de forma bibliográfica, documental e por meio de pesquisa de campo. Foram analisadas três áreas de ocupação informal em Ituiutaba: em dois casos conclui-se pela impossibilidade de regularização fundiária nas áreas, devendo, entretanto, haver a realocação das famílias que realmente necessitarem; em relação ao outro, verificou-se a possibilidade de regularização fundiária, podendo ser utilizado, para tanto, o novo instituto jurídico da legitimação fundiária, previsto na Lei Federal no $13.465 / 2017$.
\end{abstract}

Palavras-chave: Produção do espaço urbano. Regularização fundiária. Cidade ilegal. Ituiutaba-MG.

\section{PRODUCTION OF URBAN SPACE AND LAND REGULARIZATION: NOTES FROM THE STUDY OF ITUIUTABA-MG}

\begin{abstract}
In the urban space production process, problems such as housing shortage and the presence of irregular occupations are present in our cities, given the impossibility of a significant portion of the population to fit into the real estate market. This constitute a worrying reality in Brazilian cities, favoring the configuration of the so-called "illegal city". It is necessary that the land regularization policy be fostered by the Government, which can be defined as the process of integration of irregular settlements in the legal context of cities, through the adoption of legal, urban, environmental and social measures. It is the objective of this text is to analyze informal urban areas and understand the process of land regularization in the city of Ituiutaba. The methodology adopted was based on a bibliographic and documentary research. Data collection was performed bibliographically, documentally and through field research. Three areas of informal occupation in the city of Ituiutaba were analyzed: in two cases, it is concluded that it is impossible to regularize land, but there must be reallocation of the families that really need it; in relation to the other, the possibility of land regularization was verified, and the new legal institute of land legitimation, provided for in Federal Law no $13.465 / 17$, could be used for this purpose.
\end{abstract}

Keywords: Production of urban space. Land regularization. Illegal city. Ituiutaba-MG. 


\section{INTRODUÇÃO}

As cidades devem ser compreendidas no âmbito do processo de produção do espaço urbano, no qual se faz presente a interação entre ações de diversos agentes, o que enseja diversos conflitos de interesses e problemas urbanos, bem como dificuldades na implantação de um planejamento mais efetivo.

O acelerado processo de urbanização ocorrido no Brasil desencadeou vários problemas, dentre os quais a proliferação de assentamentos informais, geralmente ocupados por população de baixa renda, muitos deles sem condição de habitabilidade, em razão da limitada infraestrutura oferecida pelo Estado, comprometendo, em muitos casos, as condições socioeconômicas, o equilíbrio ambiental e a qualidade de vida da população.

Nesse contexto enquadram-se os loteamentos clandestinos ou irregulares, que cria uma situação de incerteza para grande parte da população que vive nessas áreas. De um lado, o próprio Estado, utilizando-se de áreas públicas ou institucionais, passou a construir casas para a população de baixa renda, sem preocupar-se em regularizar a sua titulação. Lado outro, alguns loteadores viram a possibilidade de se beneficiarem ao longo de anos com as irregularidades perpetradas, sobretudo diante de uma incipiente e ineficaz fiscalização.

São estas situações que configuram a denominada "cidade ilegal". Mesmo sendo áreas inseridas no espaço urbano, a população ali residente geralmente não tem acesso regular aos serviços públicos básicos, em decorrência do caráter precário das ocupações. Tais imóveis situam-se à margem do sistema legal, uma vez que não podem ser legalmente vendidos, dados em garantia ou herdados, além de não gerarem impostos, não receber o mesmo nível de investimento em infraestrutura, enfim, criando-se um contexto de problemas sociais advindos desta situação.

E é neste contexto que surge a necessidade de regularização fundiária de tais espaços urbanos, em diferentes realidades e contextos regionais do país. Seja nas pequenas cidades ou mesmo nas grandes metrópoles, tal necessidade se faz presente, em diferentes níveis e graus de complexidade. Assim, torna-se fundamental a realização de estudos que tratem do tema no sentido de contribuir tanto para a compreensão de aspectos gerais quanto específicos de cada realidade urbana.

Este texto toma como base os resultados obtidos por meio de pesquisa realizada em nível de mestrado acadêmico (NEPOMUCENO, 2019) e teve como objetivo geral analisar e compreender a produção da "cidade ilegal" e o processo de regularização fundiária em Ituiutaba, município localizado no interior do estado de Minas Gerais, mais especificamente na Região Geográfica Intermediária de Uberlândia.

Sendo assim, a primeira parte deste texto procura abordar aspectos teóricos acerca da produção do espaço urbano e de seus respectivos agentes produtores. Os interesses variados e conflitantes destes agentes levam à formação da denominada "cidade ilegal", que será foco da segunda parte deste artigo. Em seguida, a terceira parte debruçou-se sobre a situação verificada na cidade de Ituiutaba, explorando-se alguns casos de constituição de áreas de ocupação informal, além de apontar possíveis caminhos para a solução dos problemas encontrados. Por fim, a última parte do texto procurou apresentar e tecer, de forma sistematizada, as conclusões advindas desta investigação.

\section{SOBRE A PRODUÇÃO DO ESPAÇO URBANO}

A compreensão das dinâmicas que caracterizam as cidades contemporâneas não se constitui em tarefa fácil. De um lado, em virtude das cidades serem produto da interação entre diversos agentes, além de lugares de encontro e de sociabilidade. De outra ponta, por essa mesma razão, constituemse em locais em que ocorrem os mais diversos conflitos humanos.

Partindo-se da perspectiva já apresentada por Lefebvre (2006), na qual o espaço é tratado como produto material de uma dada formação social, o qual contém e está contido nas relações sociais, compreende-se que o real é historicamente construído, sendo a cidade a projeção da sociedade sobre o espaço, ou seja, expressão material.

Quando se analisa o espaço urbano deve-se considerá-lo como produto, condição e meio do processo de reprodução das relações sociais. Isto porque se, de um lado, o espaço é condição tanto da reprodução do capital quanto da vida humana, de outro ele é produto e, dessa maneira, trabalho

Caminhos de Geografia Uberlândia-MG $\quad$ v. 21, n. $75 \quad$ Jun/2020 $\quad$ p. 251-263 Página 252


materializado (CARLOS, 1994). Carlos (2005, p.27), ao analisar o papel das forças produtivas na modificação do espaço urbano, disserta:

\begin{abstract}
A cidade representa trabalho materializado; ao mesmo tempo em que representa uma determinada forma do processo de produção e reprodução de um sistema específico, portanto, a cidade é também uma forma de apropriação do espaço urbano produzido. Enquanto materialização do trabalho social, é instrumento da criação de mais-valia, é condição e meio para que se instituam relações sociais diversas. Nessa condição apresenta um modo determinado de apropriação que se expressa através do uso do solo. O modo pelo qual esse uso se dará dependerá, evidentemente, dos condicionantes do seu processo de produção. No caso da sociedade capitalista estará determinado pelo processo de troca que se efetua no mercado, visto que o produto capitalista só pode ser realizado a partir do processo de apropriação, no caso específico, via propriedade privada.
\end{abstract}

Nesse ponto, torna-se fundamental tecer algumas considerações acerca da terra urbana, uma vez que, como aponta Harvey (1980), trata-se de uma variável que merece destaque na análise do espaço urbano, pois ele se torna importante enquanto meio de acesso à cidade, seus serviços e benefícios.

No sistema capitalista o solo pode ser entendido como uma mercadoria, possuindo um valor de uso (utilidade), de moradia, por exemplo, e um valor de troca. Entretanto, ele não pode ser colocado como uma mercadoria qualquer, já que apresenta um valor de uso de elevada importância, fundamental para a garantia da manutenção da vida, do solo como moradia e como fonte de riqueza.

Torna-se, pois, necessário compreender os conceitos de valor de uso e valor de troca, visto que estes constituem a melhor maneira de entender a contradição existente na premissa do solo urbano como mercadoria. Partindo-se das ideias de Marx (apud HARVEY, 1980, p.132), tem-se que tais conceitos não podem ser entendidos de forma separada, uma vez que só existem porque se relacionam entre si:

[...] Marx começa aceitando a proposição de que cada mercadoria tem duplo aspecto de expressão na sociedade capitalista burguesa - valor de uso e valor de troca. Ele afirma que 'um valor de uso tem valor somente em uso, e realiza-se no processo de consumo' [...] e 'servem diretamente como meios de existência'. [...] Marx passa então a considerar o valor de troca. Este, sugere, aparece à primeira vista como 'relação quantitativa; a proposição pela qual valores de uso são trocados por outros.' [...] Ele conclui que a criação de valor de troca reside no processo social de aplicação de trabalho socialmente necessário aos objetos materiais (mercadorias) apropriadas para o consumo (uso) pelo homem.

De fato, a criação do valor de troca está ligada ao processo de aplicação de trabalho socialmente necessário aos objetos da natureza para a constituição de objetos materiais. Dessa feita, tem-se uma relação dialética entre o valor de uso e o valor de troca, uma vez que a mercadoria é a associação entre o valor de uso e valor de troca e, este, só adquire valor a partir do valor de uso (HARVEY, 1980).

Logo, no âmbito da produção capitalista do espaço urbano, é fundamental ter clareza sobre esta relação entre valor de uso e de troca atinentes ao solo urbano. Verifica-se, no âmbito do espaço urbano, desigualdades expressivas em relação ao acesso ao solo urbano que, por sua vez, faz parte de um conceito mais amplo, marcado pelas lógicas de produção, envolvendo diferentes usos da terra.

Esta discussão é, portanto, fundamental para a compreensão do processo de produção do espaço urbano na cidade capitalista. Conforme já ressaltado por Corrêa (1989), o espaço urbano é, entre outros aspectos, encarado como um conjunto de diferentes usos da terra justapostos entre si, os quais definem a organização espacial da cidade. Observa-se, assim, que o urbano apresenta a complexidade e os conflitos dos diversos interesses dos agentes, produzindo e reproduzindo no espaço as contradições inerentes ao modo de produção capitalista.

Nesse diapasão, a produção do espaço urbano revela-se um processo totalmente dinâmico, viabilizando o processo de reprodução do modo de produção vigente pautado no capital. Nesse contexto, o espaço urbano torna-se objeto de diferentes agentes que produzem e consomem o espaço. Consoante Corrêa (2011), no processo de produção do espaço estão inseridos agentes que possuem interesses, estratégias e práticas espaciais próprias, portadores de contradições e geradores de conflitos entre eles mesmos e com outros segmentos da sociedade, cujas ações são articuladas, resultando na própria materialização das formas e na reprodução do modo de produção.

$\begin{array}{lllll}\text { Caminhos de Geografia } & \text { Uberlândia-MG } & \text { v. 21, n. } 75 & \text { Jun/2020 } & \text { p. 251-263 Página } 253\end{array}$


De um lado existe a ação de grandes grupos, vinculados aos interesses do capital e que geralmente possuem um enorme poder de barganha frente ao Estado, que produzem a cidade como mercadoria com a finalidade específica de reprodução do capital. Para eles, a cidade é um campo de estratégias voltadas para a valorização, encarando a cidade a partir da perspectiva do valor de troca. De outro lado, encontram-se os citadinos usuários da cidade, os trabalhadores, aqueles que querem da cidade condições básicas para a vida: moradia, transporte, lazer, vida comunitária, tendo-a como valor de uso (MARICATO, 1997).

Dissertando acerca do fenômeno da produção do espaço e de seus agentes produtores, Correa (2011, p. 64) enfatiza que:

A noção de 'produção do espaço', como vimos, importa conteúdos e determinações, obriga-nos a considerar os vários níveis da realidade como momentos diferenciados da reprodução geral da sociedade em sua complexidade. Obriga-nos a considerar o sujeito da ação: o Estado, como aquele da dominação política; o capital, com suas estratégias objetivando sua reprodução continuada (e aqui nos referimos às frações do capital, o industrial, o comercial e o financeiro e suas articulações com os demais setores da economia, como o mercado imobiliário); os sujeitos sociais que, em suas necessidades e seus desejos vinculados à realização da vida humana, têm o espaço como condição, meio e produto de sua ação. Esses níveis correspondem àqueles da prática sócio-espacial real (objetiva e subjetivamente) que ganha sentido como produtora dos lugares, encerrando em sua natureza um conteúdo social dado pelas relações sociais que se realizam num espaço-tempo determinado, como um processo de produção, apropriação, reprodução da vida, da realidade e do espaço em seus descompassos, portanto, fundamentalmente, em suas contradições.

Definir as ações características de cada agente que atua na produção do espaço urbano não é tarefa simples, pois mesmo apresentando especificidades em suas estratégias, em determinadas situações eles apresentam denominadores comuns que direta ou indiretamente os unem em um mesmo processo, de modo a produzir o espaço em meio a um jogo de conflitos e de interesses particulares.

Logo, tem-se que a cidade é pensada, pretendida e construída pelos agentes responsáveis pela produção e reprodução do espaço urbano, conforme já ressaltado por Corrêa (1989), sendo que todas as formas de apropriação no urbano representam contradições e conflitos que se materializam no espaço.

Ainda na visão de Corrêa (1989), a complexidade da ação de tais agentes inclui práticas de modo geral que levam a um constante processo de reorganização espacial que se faz via incorporação de terras de uso rural ao espaço urbano; densificação do uso do solo via modificação de áreas de uso residencial para comercial, ou vice-versa; na conformação de áreas de exclusão e segregação residencial e; na legitimação, no âmbito do poder público, de todas essas práticas.

Pode-se afirmar que a atuação de todos os diferentes agentes, com seus interesses e peculiaridades próprios, resulta na produção do espaço urbano em geral, incluindo-se a "cidade ilegal", que será tratada na próxima parte do texto, uma vez que gera impactos no uso e ocupação do solo e, consequentemente, nas questões afeitas à cidade como um todo.

\section{A PRODUÇÃO DA “CIDADE ILEGAL”}

A realidade urbana brasileira é marcada pela dicotomia existente entre a ilegalidade e a formalidade, ou seja, pela cidade informal, por um lado, e pela cidade formal, por outro. De fato, o crescimento demográfico, a dinâmica imobiliária, a falta de acesso à cidade por grande parte da população, aliados à distribuição desigual de renda, ao déficit habitacional, à ausência de intervenções e políticas públicas efetivas pelo Estado, bem como à disputa por parte da iniciativa privada visando apenas o lucro, acarretaram ou contribuíram para o surgimento de ocupações irregulares, formas alternativas de acesso à habitação pelos desprovidos de outros meios.

A chamada cidade ilegal é definida pelas áreas onde estão situadas as favelas, os loteamentos irregulares e clandestinos, as ocupações de áreas protegidas ambientalmente, as ocupações coletivas de área urbana e os conjuntos habitacionais sem infraestrutura. O universo dessas ilegalidades não é uniforme, sendo possível encontrá-las desde os cortiços, herdados do passado, até os conjuntos habitacionais propostos pelo Estado para resolver o problema da habitação, os lotes comprados sem registro ou parcelados sem licença. A não uniformidade não se caracteriza apenas

Caminhos de Geografia $\quad$ Uberlândia-MG $\quad$ v. 21, n. $75 \quad$ Jun/2020 $\quad$ p. 251-263 Página 254


pelo aspecto das tipologias, das estruturas reveladas, mas também na maneira de ocupação e uso do solo, nas formas de criar, fazer e viver.

Sobre o assunto, Maricato (2001) destaca que ao longo do processo de urbanização brasileiro surgiram diversos territórios marcados pela ilegalidade e exclusão social, evidenciado nas condições de habitabilidade para a população que, sem acesso ao mercado imobiliário formal, passou a ocupar áreas públicas ou privadas, dando origem à cidade ilegal, informal ou irregular, constituída por favelas e outros processos informais presentes no espaço urbano. Frente a isso, a autora complementa que, por conseguinte, estabelece-se uma contradição entre a cidade legal (formal ou regular), como espaço destinado às classes sociais que têm acesso à moradia através do mercado imobiliário, e a cidade ilegal (informal ou irregular) que se constitui como uma alternativa popular para a problemática habitacional.

Estas formas de ocupação são resultados, sobretudo, da falta de planejamento e da má administração de nossos governos, que acabam por não contemplar as demandas habitacionais e culturais exigidas pelas necessidades urbanas e humanas de modo efetivo. De fato, o crescimento das cidades não está em situação equânime com as demandas da população, inclusive em relação à habitação, de modo que, na produção das cidades, nem sempre está inserida a produção de moradias.

Os assentamento informais são resultados, segundo Fernandes (2011), de um conjunto de fatores, tais como a baixa renda; questões socioespaciais, geralmente relacionadas à incapacidade estrutural das administrações públicas e à ausência de investimentos suficientes em infraestrutura; falta de habitação de interesse social; resultados do mercado formal, uma vez que os incorporadores imobiliários não têm interesse em produzir habitações para a população de baixa renda; clientelismo político, como quando políticos prometem escrituras definitivas de propriedade e incentivam as ocupações em terras públicas; planejamento impraticável, quando a falta de terra urbanizada gera mais informalidade porque as áreas dotadas de serviços públicos encarecem a terra, tornando-a inacessível; problemas de gestão urbana, quando os assentamentos estão fora do quadro regulamentar e normativo que regem o uso da terra; e um sistema jurídico disfuncional, pois as pessoas de baixa renda não têm acesso às informações jurídicas, à ampla resolução extrajudicial de conflitos, além do sistema judiciário ter, em muitos casos, um funcionamento obsoleto e contraditório.

A tipologia que se faz mais presente no âmbito destas ilegalidades é a favela, não só porque desafia as normas urbanísticas, mas também por afrontar o ordenamento jurídico em um de seus pontos mais sensíveis, qual seja, a propriedade privada.

Outra forma de configuração da cidade ilegal reside nos loteamentos promovidos de maneira irregular. Em geral, compreende-se por parcelamento do solo a subdivisão de uma gleba em lotes, de acordo com a Lei Federal ํ․ 6.766, de 1979, que atualmente regulamenta a matéria. De fato, um parcelamento feito sem a aprovação ou sem o registro é ilegal, sendo que a sua aprovação consiste no reconhecimento do atendimento dos requisitos urbanísticos, enquanto o registro cuida da publicidade e da individualização de cada lote, possibilitando o controle de disponibilidade desses imóveis.

Maricato (2002), ao traçar uma comparação entre as favelas e loteamentos irregulares, atesta que as primeiras se caracterizam pela completa ilegalidade na relação do morador com a posse da terra, porquanto se localizam em áreas ocupadas irregularmente, podendo ser de propriedade pública ou privada. O que difere a favela dos loteamentos ilegais é o contrato de compra e venda que garante algum direito ao morador do loteamento, que é conhecido popularmente como loteamento clandestino. Segundo Maricato (2002, p. 154), "[...] os loteamentos ilegais não constituem, geralmente, terras invadidas, mas podem apresentar diversas formas de ilegalidade em relação à documentação de propriedade ou em relação às exigências urbanísticas".

Ainda sobre esta questão dos loteamentos clandestinos, Caseiro (1979) mostra a existência de três espécies: o que loteia sem aprovação prévia do projeto e com desrespeito às normas substanciais; o que loteia sem aprovação prévia do projeto, mas respeita as normas substanciais; e o que loteia com aprovação prévia, com respeito às normas, burlando posteriormente a vigilância dos poderes públicos e comercializa os lotes com violação às normas substanciais. Já Loureiro (2000), por sua vez, ressalta que os parcelamentos clandestinos são aqueles que não foram aprovados pelos órgãos competentes, ao passo que irregulares são aqueles que foram aprovados, registrados ou não, mas implantados em desacordo com o projeto.

Em linhas gerais, os loteamentos clandestinos podem ser considerados como uma opção de moradia, normalmente para as pessoas de padrão aquisitivo menor, eis que apresentam uma possível

$\begin{array}{llllll}\text { Caminhos de Geografia } & \text { Uberlândia-MG } & \text { v. 21, n. } 75 & \text { Jun/2020 } & \text { p. 251-263 Página } 255\end{array}$


aparência de proteção da posse em razão do contrato celebrado com o loteador e custo acessível, já que uma terra ilegal custa menos que uma terra provida de equipamentos urbanos e de regularidade jurídica.

Em um cenário de omissão por parte do Poder Público, o mercado imobiliário amplia suas possibilidades de atuação pois, direta ou indiretamente, com suas práticas especulativas, acaba por provocar a expulsão da população dos seus locais de moradia. Em virtude disso, a população socialmente vulnerável abriga-se em áreas cada vez mais distantes dos centros e dos seus locais de trabalho e, nas situações mais extremas, em locais de risco e de preservação ou proteção ambiental, geralmente que não interessam ao mercado imobiliário, inclusive levando à conformação da cidade ilegal.

Esta cidade ilegal deve ser objeto da intervenção pública sob diferentes maneiras. Por um lado, o Estado, por meio dos seus instrumentos legislativos, estabelece a dicotomia legal-ilegal. Porém, por outro lado, esse mesmo Estado é muitas vezes tolerante com a ilegalidade, adotando uma relação de omissão, algumas delas proposital. Esse comportamento vai variar no espaço e no tempo em decorrência das relações travadas no âmbito de cada realidade urbana e regional. Geralmente, nas áreas mais valorizadas da cidade, o papel do Estado tende a ser mais repressivo, enquanto nas zonas menos cobiçadas pelo capital há uma espécie de cumplicidade, operando-se a política da invisibilidade do problema.

Frente ao exposto, é possível compreender que a cidade ilegal é constituída, sobretudo, para atender a necessidade vital de moradia, direito este tido como fundamental. Neste ponto, cabe ressaltar que o direito à moradia não pode ser tratado tão-somente como um abrigo representado apenas pela edificação. Deveras, a moradia deve ser segura, atender a padrões construtivos razoáveis e contemplar os serviços urbanos essenciais, especialmente os de saneamento básico, energia elétrica e coleta de lixo, pois esses elementos são indicadores de um padrão de vida digno, nos moldes estabelecidos pela Constituição Federal.

Importante destacar que habitação distingue-se de moradia, uma vez que a primeira seria um direito real que recai sobre o bem, ao passo que a segunda traz em si uma dimensão social, consistente no direito a um teto, como valor do indivíduo para elevar a sua qualidade de vida e alcançar a dignidade (CANUTO, 2010). Logo, o direito à moradia é um bem jurídico da pessoa, que integra os direitos da personalidade. Por sua vez, o direito à habitação está vinculado ao imóvel e configura uma instrumentalização do direito à moradia.

Considerando-se esta distinção, deve-se compreender que a perda ou a suspensão do direito à habitação, por exemplo, em razão da ocupação de áreas não autorizadas, deve ser feita de maneira a se preservar o direito à moradia, ainda que exercido em outro local.

Ademais, ressalta-se ainda que o direito à moradia, em toda a amplitude de seu conceito, não envolve necessariamente a propriedade privada, pois é preciso destacar o aspecto da segurança jurídica da posse, que se constitui em elemento fundamental da moradia digna. Reforça-se ainda que esta segurança jurídica pode e deve ser garantida de outras maneiras, não apenas mediante a existência de um título individual de propriedade registrado em cartório. Tanto que diversos instrumentos urbanísticos previstos no Estatuto da Cidade visando à promoção do direito à moradia estão desvinculados da propriedade, como é o caso da concessão de uso especial para fins de moradia, do direito de superfície e da concessão de direito real de uso. O mesmo se diga com relação aos institutos jurídicos da legitimação de posse e legitimação fundiária, destinados à regularização fundiária, previstos na Lei 13.465/17.

Para se compreender melhor os aspectos aqui apresentados, na próxima parte do texto buscar-se-á analisar três situações verificadas na cidade de Ituiutaba. Como já ressaltado anteriormente, a realidade urbana brasileira é ampla, diversa e complexa. Mas, por meio deste estudo, a partir da análise das características evidenciadas em uma realidade específica, pretende-se contribuir para o debate sobre a cidade ilegal e a importância da regularização fundiária.

\section{A “CIDADE ILEGAL” E A REGULARIZAÇÃO FUNDIÁRIA EM ITUIUTABA-MG}

Conforme exposto, as lógicas que envolvem o processo de produção do espaço urbano na sociedade capitalista levam à conformação de uma cidade complexa, marcada sobretudo por desigualdades socioespaciais. A conformação de uma "cidade ilegal", com forte impacto no âmbito do direito à moradia, principalmente por parte da população de baixa renda, leva à necessidade de se discutir e

$\begin{array}{lllll}\text { Caminhos de Geografia } \quad \text { Uberlândia-MG } & \text { v. 21, n. } 75 & \text { Jun/2020 } & \text { p. 251-263 Página } 256\end{array}$


analisar a questão da regularização fundiária. Essa consiste no conjunto de medidas jurídicas, urbanísticas, ambientais e sociais que buscam a regularização de assentamentos irregulares e a titulação de seus ocupantes, de maneira a garantir o direito social à moradia, o pleno desenvolvimento das funções sociais da propriedade urbana e o direito ao meio ambiente ecologicamente equilibrado (BRASIL, 2009).

Num cenário de adversidades, a regularização fundiária constitui-se em um componente importante da política urbana, uma vez que assume um significado fundamental no cumprimento do direito à segurança da posse, direito à moradia e direito à cidade. Assim, promover a regularização dos assentamentos urbanos informais precários situados nas cidades brasileiras é medida urgente e indispensável para contribuir para a diminuição da desigualdade social, erradicação da pobreza e inclusão de parte significativa da população, além de garantir o direito à moradia com dignidade.

Sobre o tema, recentemente foi promulgada a Lei Federal no 13.465/2017, que regulamenta, de forma ampla, a regularização fundiária urbana, prevendo uma série de institutos jurídicos que podem ser utilizados para esse fim, dentre eles: a legitimação fundiária e legitimação de posse, usucapião, desapropriação em favor dos possuidores, concessão de uso especial para fins de moradia, concessão de direito real de uso, entre outros.

Nesta pesquisa focou-se no estudo sobre os assentamentos e loteamentos irregulares existentes na cidade de Ituiutaba, integrantes da chamada "cidade ilegal" e que constituem núcleos urbanos informais consolidados, que ainda não foram objeto de regularização fundiária. Ao mesmo tempo em que se buscou analisar tais assentamentos, procurou-se também refletir sobre como equacionar, de forma prática, a questão da regularização fundiária nos casos analisados a partir dos institutos jurídicos de regularização fundiária previstos na Lei Federal oํ 13.465/2017. Ao mesmo tempo, analisou-se também a legislação municipal que regulamenta a matéria, além das ações empreendidas pelo Executivo para a promoção da regularização fundiária.

Conforme já mencionado anteriormente, o município de Ituiutaba está localizado no interior do estado de Minas Gerais, mais especificamente na Região Geográfica Intermediária de Uberlândia (figura 1).

Figura 1 - Ituiutaba-MG: localização na Região Geográfica Intermediária de Uberlândia, 2020.

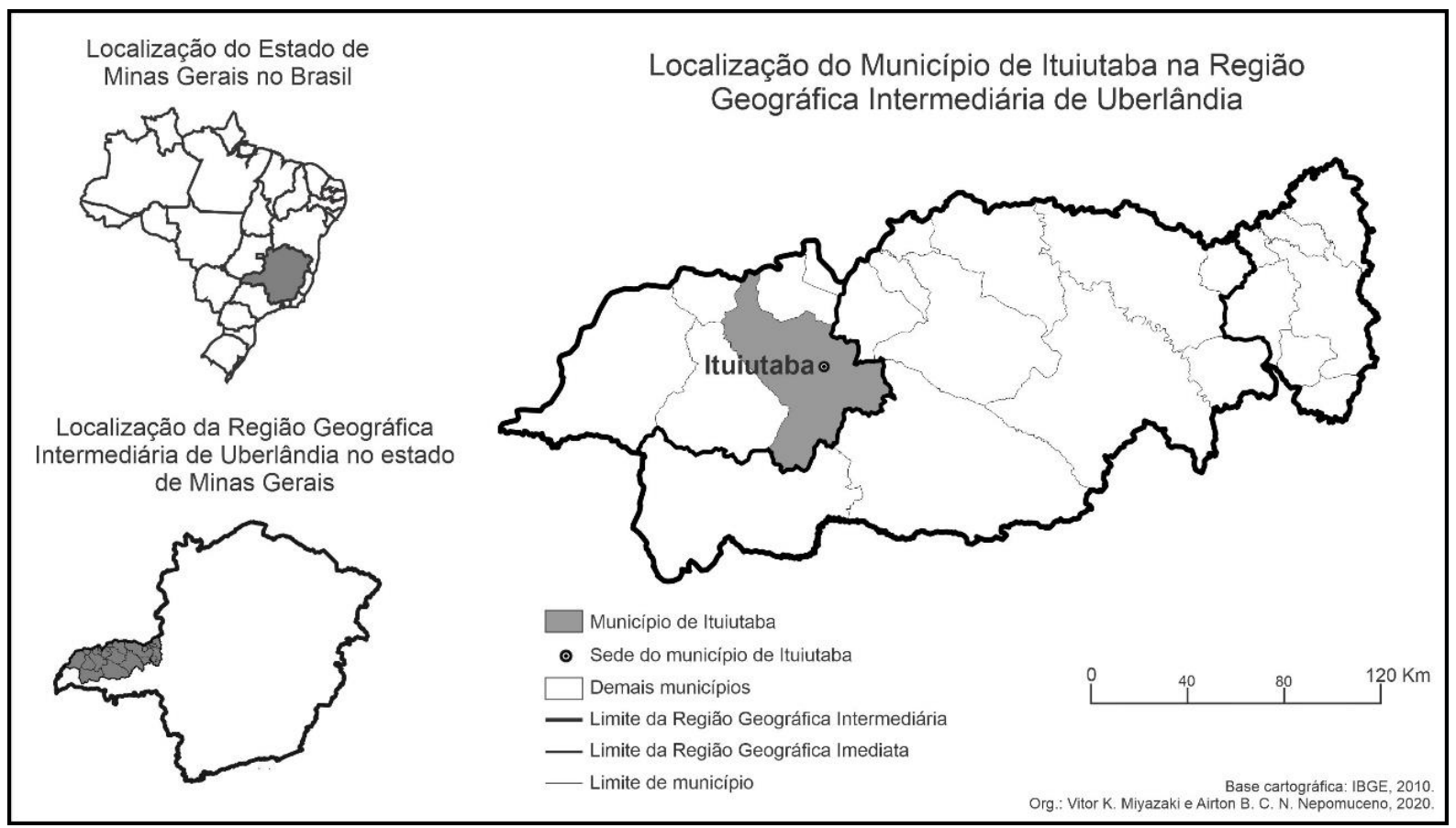

Org.: V. K. Miyazaki e A. B. C. N. Nepomuceno, 2020. Base cartográfica: IBGE, 2010.

Pelos dados do IBGE (2019), o município de Ituiutaba possui população estimada de 104.671 habitantes. Considerando-se os dados censitários de 2010 (IBGE, 2011), mais de 95\% trata-se de população urbana, totalizando 93.125 habitantes. Ao longo dos últimos anos, a cidade tem passado

$\begin{array}{llllll}\text { Caminhos de Geografia } & \text { Uberlândia-MG } & \text { v. 21, n. } 75 & \text { Jun/2020 } & \text { p. 251-263 } & \text { Página } 257\end{array}$


por transformações importantes, sobretudo em decorrência da expansão territorial resultante da implantação de quantidade expressiva de conjuntos habitacionais por meio do Programa Minha Casa Minha Vida - PMCMV, conforme já exposto por Miyazaki (2018) e Parreira e Miyazaki (2019).

Durante a realização do estudo, constatou-se que a cidade de Ituiutaba não possui grandes núcleos urbanos informais consolidados, mas, na realidade, vários lotes que não se encontram regularizados fundiariamente, principalmente de propriedade do Poder Público. Diante disso, o Executivo lançou o "Programa Minha Casa Legal", que teve como suporte a Lei Municipal $n^{\circ} 4.545 / 2017$. O programa pretendia a regularização fundiária de imóveis públicos mediante a alienação onerosa de tais bens, acaso os beneficiários atendessem determinados requisitos. Em uma avaliação sobre a eficiência do programa, com dados repassados pela Secretaria Municipal de Planejamento, constatou-se que algumas situações ou não foram tratadas diretamente pela lei municipal ou ficaram desguarnecidas, fazendo com que os processos permanecessem suspensos, sem que a Administração Municipal entregasse uma efetiva resposta aos pretensos beneficiários.

A partir do contexto acima apontado, optou-se por selecionar três casos existentes na cidade, que podem ser enquadradas como áreas urbanas informais consolidadas, as quais embasaram as análises realizados nesta pesquisa. Trata-se das seguintes áreas: o Distrito Industrial "Manoel Afonso Cancela"; trecho da Avenida Europa, localizada no Bairro Jardim Europa, em uma área de preservação permanente; e a Praça Ipiranga, localizada no Bairro Independência. A figura 2 mostra a localização de cada uma dessas áreas no contexto da cidade de Ituiutaba.

Foram realizadas visitas de campo nas três áreas urbanas selecionadas para se verificar as condições das habitações e da infraestrutura existente, além de examinados processos judiciais, inquéritos civis em trâmite no Ministério Público do Estado de Minas Gerais, processos administrativos e legislativos que com aqueles guardavam relação, e, por fim, estudos sociais realizados pelo Setor de Habitação da Secretaria Municipal de Desenvolvimento Social com os ocupantes destas áreas.

No caso do Distrito Industrial "Manoel Afonso Cancela", embora destinado para uso industrial, encontra-se ocupado irregularmente por algumas famílias para fins de moradia, situação esta que já perdura há anos. De fato, existem alguns estabelecimentos industriais no local, as quais não são muitas e não conseguem ocupar toda a extensão da área, o que contribuiu para a formação da "cidade ilegal". Os ocupantes desta área inclusive não se preocuparam em respeitar os limites dos lotes inicialmente traçados no âmbito do distrito industrial, sendo que muitos deles se sobrepõem, possuindo um traçado bastante irregular. Os imóveis estão localizados em área com vias não pavimentadas, apresentando muitas vezes características de chácaras.

De acordo com os relatórios sociais disponibilizados pela Secretaria Municipal de Desenvolvimento Social, há um total de 28 famílias que residem no local, sendo que, em alguns casos, existem de duas a três casas construídas em um mesmo lote. O relatório apontou ainda que os imóveis possuem ligações de energia e água, não tendo, contudo, esgoto, utilizando-se de fossas.

Em relação ao tempo de residência, há casos de moradores que residem no local há mais de doze anos, inclusive que lá foram assentadas com a anuência de ex-prefeito municipal, a partir da desocupação de outras áreas da cidade. Isto evidencia que o próprio Poder Público fomentou a ocupação irregular. Ao mesmo tempo, verificou-se também situações de posse mais recente, como nos casos de famílias que adquiriram lotes por até 100 mil reais, conforme informações dos relatórios sociais, que relatam até situações de contratação de empréstimos bancários para a construção de imóveis. Ressalta-se também que há relatos em que os indivíduos acabaram por adquirir o imóvel acreditando que a propriedade ser-lhes-ia realmente transferida, evidenciando que são pessoas de pouca instrução.

O caso em questão já foi submetido para apreciação do Poder Judiciário, com ações ajuizadas nos anos de 2013 e 2014 que até hoje se encontram em tramitação. Embora o Poder Público Municipal tenha notificado os ocupantes para que desocupassem os imóveis, não houve atendimento voluntário à notificação. Na realidade, verifica-se que mesmo possuindo os títulos judiciais para a reintegração de posse da área, a Prefeitura Municipal não quer sofrer os "custos políticos", pois estaria retirando pessoas de suas respectivas moradias, deixando, muitas delas, desamparadas. O cumprimento desse tipo de mandados pode envolver a necessidade de força policial, diante da resistência dos possuidores, deixando os fatos bastante expostos à opinião pública.

$\begin{array}{llllll}\text { Caminhos de Geografia } & \text { Uberlândia-MG } & \text { v. } 21, \text { n. } 75 & \text { Jun/2020 } & \text { p. 251-263 } & \text { Página } 258\end{array}$


Figura 2 - Ituiutaba-MG: localização das três áreas analisadas, 2019.

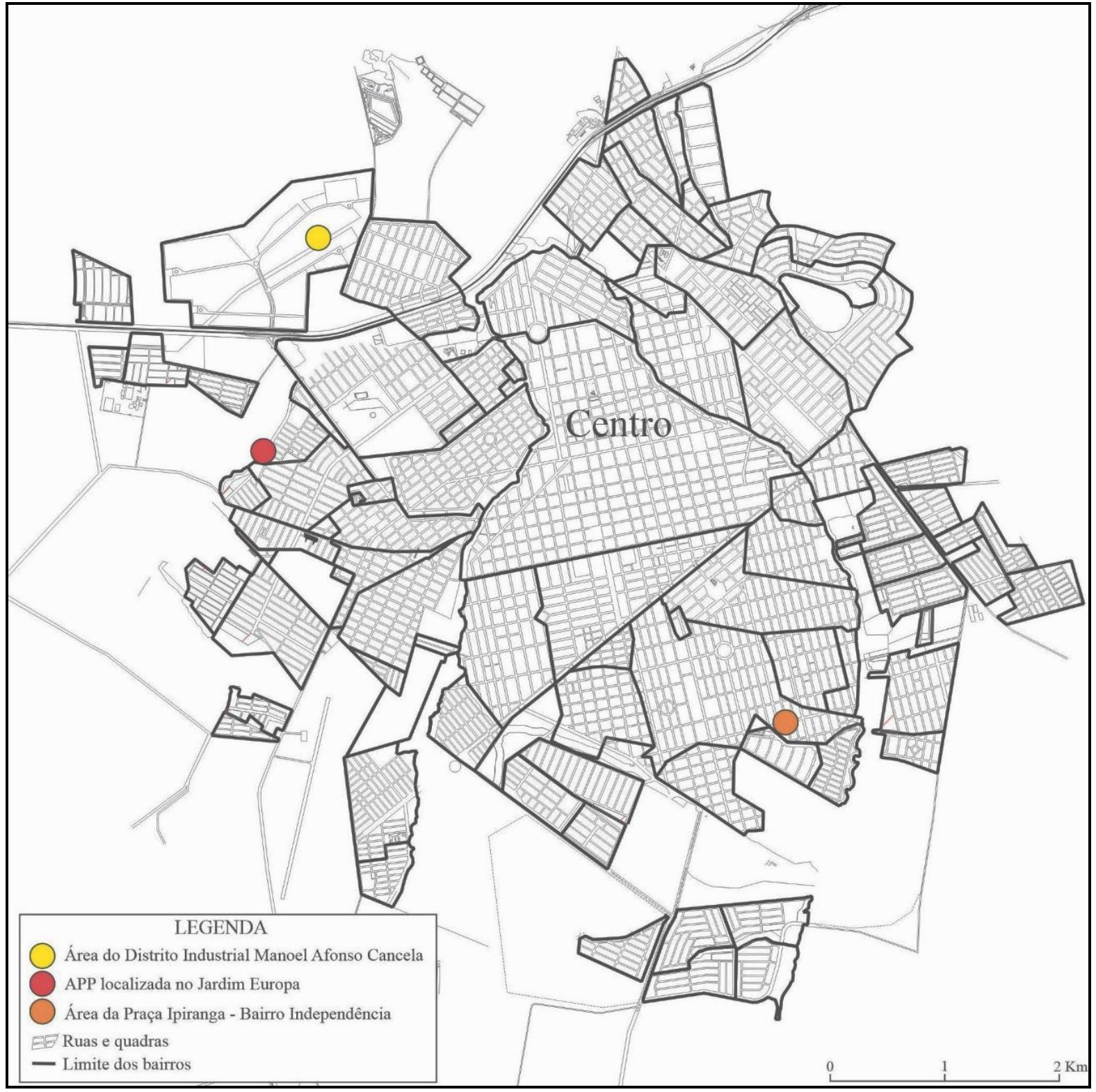

Org.: Vitor K. Miyazaki e A. B. C. N. Nepomuceno, 2019. Base cartográfica: Prefeitura Municipal de Ituiutaba, 2018.

Ressalta-se ainda que a área onde está situado o distrito industrial foi objeto de doação ao município pela Companhia de Desenvolvimento Econômico de Minas Gerais - CODEMIG. Nesta doação, o município ficou obrigado a manter a destinação do imóvel para fins exclusivamente industriais, alienando-o a empresas cuja atividade fosse compatível com o Distrito Industrial. Ainda, na ocasião, o município declarou estar ciente da existência de áreas que se encontravam ocupadas irregularmente, competindo-Ihe adotar as medidas judiciais e administrativas necessárias para regularizar a situação.

Em decorrência disso, a área em questão não pode ser objeto de regularização fundiária, dada a destinação para uso industrial. Neste caso, não é possível a ocupação irregular de tais terrenos pelos atuais detentores, sendo o caso de se cumprir os mandados de reintegração de posse autorizados judicialmente.

Obviamente o Poder Público Municipal não deve se desincumbir de promover o direito fundamental à moradia digna, sendo o caso de reassentar os possuidores em outros imóveis. Além disso, essa 
hipótese deve ocorrer apenas nos casos que tiverem, realmente, necessidade de moradia, tratandose de famílias de baixa renda.

A outra área analisada pela pesquisa diz respeito a um trecho da Avenida Europa, situado as margens do Córrego do Carmo, no Residencial Jardim Europa, em área de preservação permanente pertencente ao Poder Público Municipal. Neste caso, houve a ocupação e construção de imóveis em faixa marginal do aludido curso d'água, ao arrepio da lei, desde o ano de 2009, segundo informações contidas no Inquérito Civil no MPMG-0342.10.000138-3, em trâmite no Ministério Público do Estado de Minas Gerais.

A partir de fiscalização realizada pela Polícia Militar Ambiental em 2010, foi constatada a presença de edificações na área, sendo lavrados autos de infração em decorrência de intervenção em área de preservação permanente. O Ministério Público, por sua vez, requisitou a imediata instauração de inquérito policial para a apuração das condutas no âmbito criminal, além de perícia técnica, que concluiu que as invasões aconteceram em área de preservação permanente, nos moldes do artigo 4ํㅜㄴ, I, da Lei Federal no 12.651/2012. No caso, os danos estavam atrelados à supressão de vegetação, erosão no solo, assoreamento e deslizamentos, os quais acarretariam mudanças no leito córrego, indicando, ao final, a demolição dos bens.

Informações dos relatórios sociais mostram que há famílias residindo no local há aproximadamente nove anos. Em outros casos, os posseiros utilizam o imóvel apenas aos finais de semana, uma vez que possuem outros imóveis na cidade. Havia também imóveis em construção na área durante as visitas de campo.

Vale ressaltar que o novo Código Florestal (Lei no 12.651/2012), bem como a atual lei de regularização fundiária (Lei 13.465/2017) permite a regularização fundiária em áreas de preservação permanente, desde que atendidas algumas diretrizes. Neste caso, o projeto de regularização fundiária precisaria contemplar, além da questão atinente à moradia, a melhoria ambiental dos assentamentos. Tal medida pode ser aplicada tanto na hipótese de regularização fundiária de interesse social quanto na de interesse específico, quando há necessidade e utilidade para o Poder Público, desde que instruídos por estudo técnico detalhado.

No entanto, na área em questão, a regularização fundiária não se mostra recomendável. Primeiramente cabe destacar a perícia realizada pelo Município registrou que o caso é de demolição em virtude dos riscos futuros e consequências identificados, quais sejam: assoreamentos, deslizamentos, poluição gerada pelo lixo e esgoto, inundações e desvio do leito do córrego. Além disso, nem todos os ocupantes da área a utilizam com o fim precípuo de moradia, havendo um nítido desvio de finalidade em alguns casos, como a utilização nos finais de semana, por exemplo. Por fim, nem todas as famílias que ocupam a área são efetivamente carentes.

Assim sendo, a melhor medida é intentar-se a ação de reintegração de posse, já cogitado pelo próprio Poder Público Municipal, mas ainda não implementado, reassentando-se casos pontuais que se fizerem necessários, inclusive com base no artigo 55, IX, da Lei Complementar Municipal oㅡ 153 (Revisão do Plano do Plano Diretor de Ituiutaba), que admite expressamente essa possibilidade, e, acima de tudo, efetivando-se a devida proteção ao meio ambiente.

Mesmo que possível, em tese, a regularização fundiária em áreas de preservação permanente, devese reconhecer que uma política de ação preventiva para preservar áreas ambientalmente protegidas e que não venham a ser indevidamente ocupadas, é, com certeza, a opção mais acertada e menos penosa à sociedade, sobretudo quando associada a uma política pública que viabilize o acesso democrático e eficaz à moradia.

A terceira e última área analisada diz respeito à Praça Ipiranga, localizada no bairro Independência. $\mathrm{Na}$ realidade, constitui-se em área de $12.867,96 \mathrm{~m}^{2}$ destinada à construção do referido equipamento urbano, na ocasião da aprovação do respectivo loteamento, mas que se encontra ocupada para fins residenciais. Como não houve a instalação da praça, a área foi ocupada por diversos posseiros, além de ter sido subdividida por uma via não projetada.

A partir das visitas de campo realizadas na área, constatou-se tanto imóveis já consolidados quanto ainda em construção, com características bastante simples e, pelo perfil das construções, é possível aferir que vivem nesta área famílias de baixa renda. Ressalta-se ainda a ausência de vias pavimentadas, embora se tenha iluminação pública, além da existência de quantidade significativa de entulho e lixo na área.

\begin{tabular}{llllll}
\hline Caminhos de Geografia & Uberlândia-MG & v. 21, n. 75 & Jun/2020 & p. 251-263 Página 260
\end{tabular}


Relato de um dos moradores, que lá vive há cerca de nove anos, aponta que não possuem "escritura" e nem pagam IPTU. Porém, possuem água, energia e esgoto encanado, uma vez que foi proibido o uso de fossas no local.

Por se tratar de imóvel público com destinação, é preciso que haja a aprovação de lei para que ele possa vir a ser alienado, seja de forma gratuita ou onerosa, e, via de consequência, se for o caso, submetido à regularização fundiária. Em 2010 foi deflagrado um processo administrativo para desafetação da área, em decorrência da presença de famílias carentes na área. Porém, após a elaboração do projeto de lei, este não foi submetido à apreciação do Poder Legislativo e acabou permanecendo parado por um longo tempo, sem solução para a questão. Somente em 2015 é que um novo processo administrativo passou a tratar da questão, solicitando a desafetação da área para fins de regularização fundiária. A partir disso, houve a aprovação do projeto de lei pelo Poder Legislativo, tornando bem dominical a área onde se localizava a praça Ipiranga, sendo tal fato materializado na Lei Municipal 4.389, de 13 de novembro de 2015. Mesmo assim a situação dos ocupantes da área permanece inalterada, visto que embora tenha havido a desafetação da área, o Executivo não deu prosseguimento ao processo de regularização fundiária

Por se tratar de área ocupada por população vulnerável e carente, conforme verificado nas visitas de campo, constitui-se em caso de aplicação da regularização fundiária de interesse social pois, ao que tudo indica, é incabível cogitar-se de alienação onerosa dos lotes. Fica evidente a possibilidade de aplicação do novo instituto jurídico da legitimação fundiária, novidade prevista na Lei Federal $n$ oㅡ 13.465/2017, devendo o Município de Ituiutaba dar continuidade ao último processo administrativo instaurado, adotando-se as medidas necessárias para a realização da regularização fundiária da área.

\section{CONSIDERAÇÕES FINAIS}

Como exposto, o processo de produção do espaço urbano leva em consideração as lógicas capitalistas, sobretudo de interesse do grande capital imobiliário, o que leva à configuração de uma cidade caracterizada por processos de exclusão e segregação, onde se as desigualdades sociais se aprofundam. A deficiência ou mesmo ausência de políticas públicas voltadas para os grupos menos favorecidos economicamente agravam este cenário.

Nesse cenário, diante da impossibilidade de se acessar a moradia por meio do mercado imobiliário formal, além da ausência ou ineficiência de políticas públicas de provisão habitacional, uma considerável parcela da população acaba direcionada, ou até mesmo empurrada para a ocupação informal dos espaços urbanos.

Diante da diversidade e complexidade que caracterizam cada um dos vários casos de ocupação informal que levam à conformação da "cidade ilegal", somada à necessidade de se compreender, interpretar e aplicar a legislação existente, torna-se fundamental a realização de estudos e análises para, inclusive, fomentar a proposição de soluções para tais situações. É neste contexto que o instituto da regularização fundiária se apresenta como fundamental, uma vez que integra o âmbito de proteção do direito fundamental social à moradia, constituindo-se uma das diretrizes para a realização da política urbana brasileira. Por meio da regularização fundiária busca-se promover a moradia com segurança e dignidade à população que compõem a denominada "cidade ilegal", não se limitando somente à dimensão jurídica conceitual, do ponto de vista da regularização jurídica dos lotes apenas, mas, também, primando-se por promover melhorias no que tange aos aspectos urbanísticos, ambientais e sociais da área. Porém, é fundamental que pesquisas e estudos sejam realizados para se analisar, caso a caso, a necessidade e a viabilidade da aplicação da regularização fundiária.

Nos casos aqui analisados, situados na cidade de Ituiutaba, as áreas compreendidas pelo Distrito Industrial "Manoel Afonso Cancela" e o trecho da Avenida Europa, nas margens do Córrego do Carmo, não são possíveis de regularização fundiária. Enquanto a primeira área se encontra afetada à finalidade industrial, a segunda, em que pese ser admitida pela legislação a possibilidade de regularização fundiária em imóveis situados em áreas de preservação permanente, ficam evidentes os riscos existentes para a realização de tal ação. Notou-se também a necessidade de uma atuação mais pró-ativa por parte do Executivo, no sentido de dar cumprimento aos mandados de reintegração de posse já expedidos (Distrito Industrial) ou de seu pleito judicial (Avenida Europa/Córrego do Carmo), realocando a população realmente vulnerável em outro local ou imóvel. 
Já em relação a ocupação existente na Praça Ipiranga, concluiu-se pela possibilidade de regularização fundiária, inclusive podendo ser utilizado o novo instituto jurídico da legitimação fundiária. Conforme a documentação analisada, a área já está desafetada e é ocupada por população extremamente carente, cabendo ao Município viabilizar a sua regularização fundiária.

Ainda no âmbito do Município de Ituiutaba, cabe ressaltar que foi aprovada a Lei Complementar Municipal no 153/2018, que versa sobre a revisão do Plano Diretor Municipal de Ituiutaba, a qual consagrou dispositivos importantes. Destaca-se, por exemplo, a obrigatoriedade de elaboração de um Plano Municipal de Habitação de Interesse Social, além da criação de um Sistema Municipal de Regularização Fundiária e do respectivo plano. Porém, o sucesso de tais instrumentos depende, sobretudo, de engajamento político por parte do Poder Público Municipal, que deve pautar sua atuação em adstrito respeito aos princípios administrativos consagrados em nossa Constituição Federal, quais sejam: legalidade, impessoalidade, moralidade, publicidade e eficiência, bem como atuar em consonância com as regras e princípios trazidos pela política urbana constitucional, Estatuto da Cidade e Plano Diretor. Por fim, em linhas gerais, conclui-se que ainda há muito a se fazer acerca da questão da regularização fundiária na cidade de Ituiutaba.

\section{REFERÊNCIAS}

BRASIL. Lei no. 6.766, de 19 de dezembro de 1979. Diário Oficial da União. Brasília, DF, 20 dez. 1979. Disponível em: <http://www.planalto.gov.br/ccivil_03/leis//6766.htm>. Acesso em: 30 mai. 2019.

BRASIL. Lei no. 11.977, de 7 de julho de 2009. Diário Oficial da União. Brasília, DF, 7 jul. 2009. Disponível em: <http://www.planalto.gov.br/ccivil_03/_ato2007-2010/2009/lei/l11977.htm>. Acesso em: 14 mar. 2019.

BRASIL. Lei oㅡ. 12.651, de 25 de maio de 2012. Diário Oficial da União. Brasília, DF, 28 mai. 2012. Disponível em: <http://www.planalto.gov.br/ccivil_03/_ato2011-2014/2012/lei/l12651.htm>. Acesso em: 30 mai. 2019.

BRASIL. Lei no. 13.465, de 11 de julho de 2017. Diário Oficial da União. Brasília, DF, 11 jul. 2017. Disponível em: <http://www.planalto.gov.br/ccivil_03/_ato2015-2018/2017/lei/l13465.htm>. Acesso em: 08 mar. 2019.

CÂMARA MUNICIPAL DE ITUIUTABA. Lei Municipal no 4.389, de 13 de novembro de 2015. Disponível em: <http://www.ituiutaba.mg.leg.br/leis/lei-municipal/leis-ordinarias/ano-de-2015/lei-n-4389-de-13-de-novembro-de-2015/view>. Acesso em: 30 mai. 2019.

CÂMARA MUNICIPAL DE ITUIUTABA. Lei Municipal no 4.545, de 15 de dezembro de 2017. Disponível em: <http://www.ituiutaba.mg.leg.br/leis/lei-municipal/leis-ordinarias/ano-de-2017/lei-ndeg4-545-de-15-de-dezembro-de-2017/view>. Acesso em: 30 mai. 2019.

CÂMARA MUNICIPAL DE ITUIUTABA. Lei Municipal Complementar no 153, de 13 de julho de 2018. Disponível em: <http://www.ituiutaba.mg.leg.br/leis/lei-municipal/leis-complementares/ano-de2018/lei-complementar-no-153-de-13-de-julho-de-2018/view>. Acesso em: 30 mai. 2019.

CANUTO, E. M. A. Direito à Moradia Urbana: aspectos da dignidade da pessoa humana. Belo Horizonte: Fórum, 2010.

CARLOS, A. F. A. A (re)produção do Espaço Urbano. São Paulo: Edusp, 1994.

CARLOS, A. F. A. A Cidade. 8. ed. São Paulo: Contexto, 2005.

CASEIRO, L. Loteamentos Clandestinos. Consequências penais. São Paulo: Universitária de Direito, 1979.

CORRÊA, R. L. O Espaço Urbano. São Paulo: Ática,1989.

CORRÊA, R. L. Sobre agentes sociais, escala e produção do espaço: um texto para discussão. In: CARLOS, A. F. A; SOUZA, M.L.; SPOSITO, M.E.B. (Org.). A produção do espaço urbano: agentes e processos, escalas e desafios. São Paulo: Contexto, 2011.

FERNANDES, E. Regularização de assentamentos informais na América Latina. Foco em políticas fundiárias. Lincoln Institute of Land Policy. 2011. Disponível em: $<$ https://www.lincolninst.edu/sites/default/files/pubfiles/regularizacao-assentamentos-informaisfull_1.pdf>. Acesso em: 20 mar. 2019.

$\begin{array}{llllll}\text { Caminhos de Geografia } & \text { Uberlândia-MG } & \text { v. 21, n. } 75 & \text { Jun/2020 } & \text { p. 251-263 Página } 262\end{array}$


HARVEY, David. A Justiça Social e a Cidade. São Paulo: Hucitec, 1980.

IBGE. Censo Demográfico - Características da população e dos domicílios: resultados do universo. Rio de Janeiro: IBGE, 2011.

IBGE. Estimativas da população residente para os municípios e para as unidades da federação com data de referência em 1ํ de julho de 2019. Rio de Janeiro: IBGE, 2019.

LEFEBVRE, H. A produção do espaço urbano. Trad. Doralice Barros Pereira e Sérgio Martins (do original La production de l'espace, 4.ed. Paris: Éditions Anthropos, 2000). Primeira versão - fev. 2006.

LOUREIRO, F. E. Loteamentos clandestinos. Prevenção e repressão. Revista de Direito Imobiliário. São Paulo: Revista dos Tribunais, n. 48, ano 23, 2000.

MARICATO, E. Habitação e Cidade. São Paulo: Atual, 1997.

MARICATO, E. Metrópole periférica, desigualdade social e meio ambiente. In: DINIZ, N.; SILVA, M.; VIANA, G. (Orgs.) O Desafio da Sustentabilidade: um debate socioambiental no Brasil. São Paulo: Fundação Perseu Abramo, 2001.

MARICATO, E. As ideias fora do lugar e o lugar fora das ideias. Planejamento urbano no Brasil. In ARANTES, O.; MARICATO, E.; VAINER, C. A cidade do Pensamento Único. 3. ed. Rio de Janeiro: Editora Vozes, 2002.

MIYAZAKI, V. K. Morfologia urbana e estruturação da cidade em Ituiutaba-MG: análise das transformações no período 2000-2018. Brazilian Geopraphical Journal. Ituiutaba: Edufu, v. 8, p. 2339, 2018.

NEPOMUCENO, A. B. C. N. O instituto da regularização fundiária na cidade de Ituiutaba-MG. 2019. 163 f. Dissertação (Mestrado em Geografia do Pontal) - Universidade Federal de Uberlândia, Ituiutaba, 2019. Disponível em: http://doi.org/10.14393/ufu.di.2019.2538.

PARREIRA, S. B. S.; MIYAZAKI, V. K. Produção do espaço urbano e estruturação da cidade: estudo sobre o desenvolvimento de áreas comerciais em conjuntos habitacionais de Ituiutaba-MG. In: PORTUGUEZ, A. P; OLIVEIRA JÚNIOR, A.; MIYAZAKI, V. K. (Org.). Olhares da Geografia Brasileira: dinâmicas ambientais e questões sociais na atualidade. Ituiutaba: Barlavento, 2019, p. 317-346.

Recebido em: 01/02/2020

Aceito para publicação em: 24/04/2020 